\title{
Clinical characteristics of 16 patients with COVID-19 infection outside of Wuhan, China: a retrospective, single-center study
}

\author{
Wenbin $\mathrm{Hu}^{1}$, Xuefang Chen ${ }^{2}$, Binjun $\mathrm{He}^{3}$, Shunda Yuan ${ }^{4}$, Xing Zhang ${ }^{5}$, Guofeng Wu ${ }^{6}$, Jingjing Liu ${ }^{7}$, \\ Liang $\mathrm{Xu}^{8}$, Wei Cha ${ }^{9}$, Mengmin Xu ${ }^{8}$, Xiaojun Sun ${ }^{8}$, Huajiang Shen ${ }^{10}$ \\ ${ }^{1}$ Department of Cardiothoracic Surgery, ${ }^{2}$ Department of Science and Education, Affiliated Hospital of Shaoxing University (The Shaoxing Municipal \\ Hospital), Shaoxing 312000, China; ${ }^{3}$ Department of Thoracosurgery, Shaoxing People's Hospital, Zhejiang University School of Medicine, Shaoxing \\ 312000, China; ${ }^{4}$ Department of Cardiothoracic Surgery, ${ }^{5}$ Department of Gastroenterology, ${ }^{6}$ Department of Pulmonary, ${ }^{7}$ Department of Cardiology, \\ ${ }^{8}$ Department of Respiratory, ${ }^{9}$ Department of Cardiology, ${ }^{10}$ Department of Infection, Affiliated Hospital of Shaoxing University (The Shaoxing \\ Municipal Hospital), Shaoxing 312000, China \\ Contributions: (I) Conception and design: W Hu, H Shen, B He, S Yuan; (II) Administrative support: H Shen, X Chen, X Sun, M Xu; (III) Provision \\ of study materials or patients: W Hu, X Zhang, G Wu, J Liu; (IV) Collection and assembly of data: W Hu, L Xu, W Cha; (V) Data analysis and \\ interpretation: All authors; (VI) Manuscript writing: All authors; (VII) Final approval of manuscript: All authors. \\ Correspondence to: Huajiang Shen. Department of Infection, Affiliated Hospital of Shaoxing University (The Shaoxing Municipal Hospital), Shaoxing \\ 312000, China. Email: shenhuajiang2@126.com.
}

Background: Since early December 2019, the 2019 novel coronavirus (COVID-19) has emerged in Wuhan and spread rapidly in China. We aimed to describe the clinical characteristics of hospitalized patients with confirmed COVID-19 infection in Shaoxing, and provide an insight into the treatment of COVID-19 across China and elsewhere.

Methods: In this retrospective, single-center, study, we enrolled 16 patients with laboratory-confirmed COVID-19 admitted to the Affiliated Hospital of Shaoxing University between February 24 and January 25, 2020. Epidemiological, demographic, clinical, laboratory, radiological feature, and treatment data were all collected. Outcomes were followed up until March 16, 2020.

Results: Among the 16 patients with COVID-19 infection, 11 patients (68.8\%) had traveled or lived in Wuhan or surrounding areas, and $2(12.5 \%)$ patients had exposure to patients with confirmed COVID-19 infection. The average age of the patients was 44.1 (16.5) years, and there were 10 women $(62.5 \%)$ and 6 men $(37.5 \%)$. More than half had chronic diseases [9 (56.3\%)]. The most common symptoms at onset of COVID-19 infection were fever [12 (75\%)] and cough [8 (50\%)]; 11 (68.8\%) patients had lymphopenia, and $12(75 \%)$ had elevated C-reactive protein. On admission, abnormalities in computed tomography (CT) or chest X-ray images were revealed among all patients, and 11 (68.8\%) of 16 patients had bilateral involvement. All patients were given psychological counseling, 15 (93.8\%) patients were administered with antiviral therapy, $8(50 \%)$ received empirical antibiotic treatment, and $5(31.3 \%)$ patients were given systematic corticosteroids. Complications included acute respiratory distress syndrome (ARDS) requiring non-invasive mechanical ventilation [1 (6.3\%)], acute respiratory injury [4 $(25 \%)]$, acute renal injury [1 $(6.3 \%)]$, septic shock [1 (6.3\%)], liver dysfunction [5 (31.3\%)], electrolyte disturbance [8 (50.0\%)], and hospital-acquired pneumonia [3 (18.8\%)]. None of the 16 patients died of COVID-19 pneumonia.

Conclusions: Compared with the symptoms of the initial patients with COVID-19 infection in Wuhan, the symptoms of the patients from Shaoxing city were relatively mild. Currently, there is no effective drug treatment or vaccine for COVID-19, and psychological counseling cannot be ignored. Drugs and vaccines against COVID-19 infection need to be developed as soon as possible.

Keywords: 2019 novel coronavirus (COVID-19); severe acute respiratory syndrome coronavirus-2 (SARS-CoV-2); infection; pneumonia 
Submitted Mar 23, 2020. Accepted for publication May 11, 2020.

doi: $10.21037 / \mathrm{atm}-20-3422$

View this article at: http://dx.doi.org/10.21037/atm-20-3422

\section{Introduction}

In early December 2019, a cluster of patients with an initial diagnosis of pneumonia of an unknown etiology were admitted to hospitals in Wuhan, Hubei province, China (1). The most common symptoms at onset of COVID-19 infection were fever and cough. Most patients worked at or lived around the local Huanan seafood wholesale market where wild animals were sold illegally $(2,3)$. In the early stage of this virus that closely resembled pneumonia, severe symptoms of acute respiratory infection appeared. Some patients progressed rapidly into acute respiratory distress syndrome (ARDS), acute respiratory failure, and other serious complications. This type of pneumonia caused by the 2019 novel coronavirus disease (COVID-19) is a highly infectious disease that has spread rapidly throughout Wuhan to other provinces in China and to countries around the world. The ongoing outbreak has been declared a global public health emergency by the World Health Organization (WHO) (4). As of February 29, 2020, the total number of COVID-19 patients has risen rapidly to 79,968 in China, with 3,387 medical workers infected, and 2,873 (3.6\%) deaths.

Starting January 26, 2020, our center became one of the designated hospitals for treating COVID-19 pneumonia, and 16 laboratory-confirmed COVID-19 infection patients have been admitted to our center thus far. In this study, we retrospectively collected and analyzed the detailed clinical data from these patients, in order to gain insight into the treatment of COVID-19 across China and around the world.

We present the following article in accordance with the STROBE reporting checklist (available at http://dx.doi. org/10.21037/atm-20-3422).

\section{Methods}

\section{Study design and patients}

For this retrospective, single-center study, we analyzed of medical records of 16 patients with COVID-19 pneumonia admitted to the Affiliated Hospital of Shaoxing University from February 24 to January 25, 2020. Diagnosis of COVID-19 pneumonia was based on the New Coronavirus
Pneumonia Prevention and Control Program (Fifth edition) published by the National Health Commission of China. All 16 patients with COVID-19 pneumonia tested positive for severe acute respiratory syndrome (SARS) coronavirus 2 (SARS-CoV-2) at the local center for disease control based on samples from pharyngeal swab, nasal swab, and sputum. The clinical outcomes were monitored up to March 10, 2020, which was the final date of follow-up.

The study was approved by the Institutional Review Board of the Affiliated Hospital of Shaoxing University, and written informed consent was obtained from patients involved before enrolment.

\section{Data collection}

We reviewed clinical medical records, nursing records, laboratory findings, and radiological examinations for all patients with laboratory-confirmed 2019 novel corona virus (2019-nCoV) infection. Clinical outcomes were followed up until March 10, 2020. The admission data of these patients were obtained and curated with standardized data collection forms. Two researchers independently reviewed the data collection forms to verify their accuracy. Nasal swab, throat swab, and sputum samples from the upper respiratory tract of all patients were collected and tested for COVID-19 by use of real-time reverse transcriptase polymerase chain-reaction (RT-PCR) with the Chinese Center for Disease Control and Prevention (CDC) recommended kit. The primers and probe target to envelope gene of SARS-CoV-2 as follows: forward primer CCCTGTGGGTTTTACACTTAA; reverse primer ACGATTGTGCATCAGCTGA; and the probe 5'-FAMCCGTCTGCGGTATGTGGAAAGGTTATGGBHQ1-3'. All specimens were processed simultaneously at the Shaoxing municipal CDC and Zhejiang provincial CDC. The positive confirmed cases of COVID-19 infection were defined as those with positive results in both laboratories. All patients confirmed with COVID-19 were treated in the isolation ward, and almost all patients were administered antiviral therapy, including oseltamivir, arbidol, chloroquine phosphate, and lopinavir and ritonavir tablets. Half of the patients received empirical antibiotic treatment and a few severe patients were given systematic 
Table 1 Demographics and baseline characteristics of 16 patients with COVID-19 pneumonia

\begin{tabular}{|c|c|}
\hline Variable & All patients $(n=16)$ \\
\hline \multicolumn{2}{|l|}{ Age, years } \\
\hline Mean (SD) & $44.1(16.5)$ \\
\hline Range & $5-70$ \\
\hline$\leq 14$ & $1(6.3)$ \\
\hline $20-29$ & $2(12.5)$ \\
\hline 30-39 & $2(12.5)$ \\
\hline $40-49$ & $4(25.0)$ \\
\hline $50-59$ & $5(31.3)$ \\
\hline $60-69$ & $1(6.3)$ \\
\hline$\geq 70$ & $1(6.3)$ \\
\hline \multicolumn{2}{|l|}{ Sex } \\
\hline Female & $10(62.5)$ \\
\hline Male & $6(37.5)$ \\
\hline \multicolumn{2}{|l|}{ Epidemiological history } \\
\hline Exposure to relevant environment* & $11(68.8)$ \\
\hline Close contact with infected patient & $2(12.5)$ \\
\hline No relation with Hubei Province & $3(18.8)$ \\
\hline \multicolumn{2}{|l|}{ Chronic medical illness } \\
\hline Hypertension & $5(31.3)$ \\
\hline Diabetes & $2(12.5)$ \\
\hline Malignancy & $1(6.3)$ \\
\hline Anemia & $1(6.3)$ \\
\hline Malnutrition & $1(6.3)$ \\
\hline Hepatic dysfunction & $1(6.3)$ \\
\hline Obsolete pulmonary tuberculosis & $1(6.3)$ \\
\hline Fatty liver & $3(18.8)$ \\
\hline
\end{tabular}

Data are presented as $\mathrm{n}(\%)$ and means (SD) unless specified otherwise. *, exposure to relevant environment refers to having travel in or lived in Wuhan or surrounding areas.

corticosteroids or immunoglobulin therapy

We collected data on age, gender, epidemiological history, chronic medical history (hypertension, diabetes, chronic pulmonary disease, chronic cardiac disease, and malignancy), symptoms from onset to admission (fever, cough, angina, myalgia, dyspnea, rhinorrhea, and diarrhea), vital signs at the isolation ward (temperature, heart rate, respiratory rate, and blood pressure), laboratory values at the fever clinic and during hospitalization (neutrophil count, lymphocyte count, platelet count, arterial blood gas analysis, liver function, renal function, coagulation function, cytokines, and antibodies of SARS-CoV-2), radiology data from onset to recovery [thoracic computed tomography (CT), and chest X-ray], treatment (oxygen therapy, antipyretics, antiviral drugs, antibacterial drugs, corticosteroids, and immunoglobulins).

\section{Statistical analysis}

All collected clinical date were analyzed by SPSS 21.0, and expressed as mean (SD) for continuous variables and number (\%) for categorical variables.

\section{Role of the funding source}

The funder of the study had no role in the study design, data collection, data analysis, data interpretation, or writing of the report. The corresponding authors assume full authority over all the data in the study and hold all responsibility for the decision to submit for publication.

\section{Results}

\section{Clinical characteristics}

Ultimately, 16 patients with COVID-19 pneumonia were included in this study, 2 of whom were mother and son, and 2 of whom were husband and wife. A total of 11 patients $(68.8 \%)$ had traveled or lived in Wuhan or surrounding areas, and $2(12.5 \%)$ patients had exposure to patients with confirmed COVID-19 infection (Table 1). The group had a mean age of 44.1 (16.5) years, and included 10 women $(62.5 \%)$ and 6 men (37.5\%) (Table 1). More than half had chronic diseases [9 (56.3\%)], including hypertension [5 $(31.3 \%)$ ], diabetes [2(12.5\%)], malignancy [1 (6.3\%)], anemia [1 $(6.3 \%)]$, malnutrition $[1(6.3 \%)]$, hepatic dysfunction $(1(6.3 \%))$, obsolete pulmonary tuberculosis [1 $(6.3 \%)$ ], and fatty liver [3 (18.8\%)].

The most common symptoms at onset of COVID-19 infection were fever [12 (75\%)] and cough [8 (50\%)] (Table 2). Less common symptoms included shortness of breath, sore throat, muscle pain, chest tightness, rhinorrhea, exhaustion, diarrhea, and headache (Table 2). In the course of treatment, a few patients presented with organ function damage, including 1 (6.3\%) with ARDS, 4 (25\%) with 


\section{Page 4 of 9}

Table 2 Clinical characteristics and treatment of patients with COVID-19 pneumonia

\begin{tabular}{|c|c|}
\hline Characteristic & All patients $(n=16)$ \\
\hline \multicolumn{2}{|l|}{ Symptoms } \\
\hline Fever & $12(75.0)$ \\
\hline Cough & $8(50.0)$ \\
\hline Expectoration & $4(25.0)$ \\
\hline Sore throat & $2(12.5)$ \\
\hline Muscle pain & $1(6.3)$ \\
\hline Shortness of breath & $2(12.5)$ \\
\hline Chest tightness & $2(12.5)$ \\
\hline Rhinorrhea & $2(12.5)$ \\
\hline Exhaustion & $2(12.5)$ \\
\hline Diarrhea & $3(18.8)$ \\
\hline Headache & $2(12.5)$ \\
\hline \multicolumn{2}{|l|}{ Comorbidities } \\
\hline Acute respiratory distress syndrome & $1(6.3)$ \\
\hline Acute respiratory injury & $4(25.0)$ \\
\hline Septic shock & $1(6.3)$ \\
\hline Liver dysfunction & 5 (31.3) \\
\hline Renal dysfunction & $1(6.3)$ \\
\hline Electrolyte disturbance & $8(50.0)$ \\
\hline Hospital-acquired pneumonia & $3(18.8)$ \\
\hline Death & 0 \\
\hline \multicolumn{2}{|l|}{ Chest X-ray and CT findings } \\
\hline Unilateral pneumonia & 5 (31.3) \\
\hline Bilateral pneumonia & $11(68.7)$ \\
\hline \multicolumn{2}{|l|}{ Treatment } \\
\hline Oxygen therapy & $14(87.5)$ \\
\hline High flow nasal cannula & $4(25.0)$ \\
\hline Common nasal cannula & $10(62.5)$ \\
\hline Mechanical ventilation (non-invasive) & $1(6.3)$ \\
\hline Antiviral therapy & 15 (93.8) \\
\hline Antibiotic therapy & $8(50.0)$ \\
\hline Single antibiotic & $3(18.8)$ \\
\hline Combined antibiotics & $5(31.3)$ \\
\hline Glucocorticoids & $5(31.3)$ \\
\hline Immunoglobulin therapy & $3(18.8)$ \\
\hline Psychological counseling & 15 (93.8) \\
\hline
\end{tabular}

Data are presented as $\mathrm{n}(\%)$.

\section{Hu et al. Clinical characteristics of the COVID-19 in Shaoxing city}

acute respiratory injury, 1 (6.3\%) with acute renal injury, 1 (6.3\%) with septic shock, 5 (31.3\%) with liver dysfunction, $8(50.0 \%)$ with electrolyte disturbance, and 3 (18.8\%) with hospital-acquired pneumonia (Table 2).

\section{Laboratory and radiologic findings}

Data from laboratory tests on admission showed that lymphocytes were below the normal range in 11 (68.8\%) patients. Only 1 (6.3\%) patient had leucocytes above the normal range. D-dimer level increase occurred in all $5(31.3 \%)$ of the severe patients. Levels of alanine aminotransferase (ALT) and aspartate aminotransferase (AST) were increased in 5 (31.3\%) of 16 patients, including $4(80 \%)$ of 5 severe patients and $1(6.3 \%)$ of 11 general patients. Meanwhile, 1 (6.3\%) patient had elevated concentrations of serum creatinine and blood urea nitrogen, and 12 patients $(75 \%)$ had increased concentrations of C-reactive protein $(>10 \mathrm{mg} / \mathrm{L})$. Most patients had normal serum levels of procalcitonin [15 (93.8\%)], and only 1 $(6.3 \%)$ of 3 patients who developed secondary infection had procalcitonin higher than $0.5 \mathrm{ng} / \mathrm{mL}$ (Table 3).

On admission, abnormalities in CT or chest X-ray images were revealed among all patients. A total of 11 $(68.8 \%)$ of the 16 patients had bilateral involvement (Table 1), with the lesion commonly being located in the subpleural and lower lobe of lungs. In the early stages, chest CT mainly showed multiple small ground glass opacities and interstitial changes (Figure 1). As the disease continued, the lesion gradually progressed to multiple ground glass infiltrations in the lungs and appeared as subsegmental areas of consolidation, with the lobular septum becoming thicker and fibrosis being visible. Bright spots on the bronchogram could also be seen in the lung tissue area of the lesion, and this is referred to as bronchoinflation sign. After effective treatment or improvement of the patient's immunity, the lesions in lungs were gradually absorbed, with more fibrosis being visible (Figure 2).

\section{Treatment and outcomes}

All patients were treated in the isolation ward; 16 patients were given psychological counseling, 4 (25\%) patients were treated with high flow oxygen through the nasal cannula, and $10(62.5 \%)$ were treated with common nasal cannula. For symptoms, 5 patients developed severe pneumonia, 1 of whom had ARDS requiring non-invasive mechanical ventilation. The ventilator adopted the $\mathrm{S} / \mathrm{T}$ mode, the 
Table 3 Laboratory results of patients with COVID-19 pneumonia

\begin{tabular}{|c|c|}
\hline Variable & All patients $(n=16)$ \\
\hline \multicolumn{2}{|l|}{ Blood routine } \\
\hline $\begin{array}{l}\text { Leucocytes } \\
\left(\times 10^{9} \text { per L; normal range } 3.5-9.5\right)\end{array}$ & $3.1(2.9)$ \\
\hline Increased & $1(6.3 \%)$ \\
\hline Decreased & $5(31.3 \%)$ \\
\hline $\begin{array}{l}\text { Neutrophils } \\
\left(\times 10^{9} \text { per L; normal range } 1.8-6.3\right)\end{array}$ & $3.3(2.9)$ \\
\hline Increased & $1(6.3 \%)$ \\
\hline Decreased & $2(12.5 \%)$ \\
\hline $\begin{array}{l}\text { Lymphocytes } \\
\left(\times 10^{9} \text { per L; normal range } 1.1-3.2\right)\end{array}$ & $0.9(0.4)$ \\
\hline Decreased & $11(68.8 \%)$ \\
\hline $\begin{array}{l}\text { Platelets } \\
\left(\times 10^{9} \text { per L; normal range } 125-350\right)\end{array}$ & $214.3(101.1)$ \\
\hline Increased & $3(18.6 \%)$ \\
\hline Decreased & $3(18.6 \%)$ \\
\hline $\begin{array}{l}\text { Hemoglobin } \\
\text { (g/L; normal range120-150) }\end{array}$ & $125.4(16.8)$ \\
\hline Decreased & $4(25 \%)$ \\
\hline \multicolumn{2}{|l|}{ Coagulation function } \\
\hline $\begin{array}{l}\text { Activated partial thromboplastin time } \\
\text { (s; normal range } 26.0-45.0 \text { ) }\end{array}$ & $36.1(8.7)$ \\
\hline Increased & $1(6.3 \%)$ \\
\hline Decreased & $2(12.5 \%)$ \\
\hline $\begin{array}{l}\text { Prothrombin time } \\
\text { (s; normal range 11.0-15.0) }\end{array}$ & $12.7(2.4)$ \\
\hline Increased & $2(12.5 \%)$ \\
\hline Decreased & $3(18.6 \%)$ \\
\hline D-dimer ( $\mu \mathrm{g} / \mathrm{L}$; normal range 0-500) & $531.9(535.2)$ \\
\hline Increased & $5(31.3 \%)$ \\
\hline \multicolumn{2}{|l|}{ Blood biochemistry } \\
\hline Albumin (g/L; normal range $40.0-55.0)$ & $35.1(5.8)$ \\
\hline Decreased & $13(81.3 \%)$ \\
\hline $\begin{array}{l}\text { Total bilirubin } \\
\text { ( } \mu \mathrm{mol} / \mathrm{L} ; \text { normal range } 6.1-20.5)\end{array}$ & $14.6(7.9)$ \\
\hline Increased & $3(18.6 \%)$ \\
\hline
\end{tabular}

Table 3 (continued)
Table 3 (continued)

\begin{tabular}{|c|c|}
\hline Variable & All patients $(n=16)$ \\
\hline $\begin{array}{l}\text { Alanine aminotransferase } \\
\text { (U/L; normal range 9.0-50.0) }\end{array}$ & $57.4(31.9)$ \\
\hline Increased & 5 (31.3\%) \\
\hline $\begin{array}{l}\text { Aspartate aminotransferase } \\
\text { (U/L; normal range } 15.0-40.0)\end{array}$ & $31.0(19.1)$ \\
\hline Increased & $5(31.3 \%)$ \\
\hline $\begin{array}{l}\text { Serum creatinine } \\
(\mu \mathrm{mol} / \mathrm{L} ; \text { normal range } 59.0-104.0)\end{array}$ & $66.1(20.8)$ \\
\hline Increased & $1(6.3 \%)$ \\
\hline Decreased & $7(43.8 \%)$ \\
\hline $\begin{array}{l}\text { Blood urea nitrogen } \\
\text { (mmol/L; normal range 3.1-8.0) }\end{array}$ & $3.5(2.3)$ \\
\hline Increased & $1(6.3 \%)$ \\
\hline Decreased & $5(31.3 \%)$ \\
\hline $\begin{array}{l}\text { Creatine kinase } \\
\text { (U/L; normal range 26.0-190.0) }\end{array}$ & $115.9(114.7)$ \\
\hline Increased & $2(12.5 \%)$ \\
\hline Decreased & $4(25 \%)$ \\
\hline $\begin{array}{l}\text { Lactate dehydrogenase } \\
\text { (U/L; normal range 12.0-250.0) }\end{array}$ & $211.5(71.3)$ \\
\hline Increased & $4(25 \%)$ \\
\hline $\begin{array}{l}\text { Glucose } \\
\text { (mmol/L; normal range 3.90-6.11) }\end{array}$ & $7.8(3.0)$ \\
\hline Increased & $7(43.8 \%)$ \\
\hline \multicolumn{2}{|l|}{ Infection-associated } \\
\hline $\begin{array}{l}\text { Procalcitonin } \\
\text { (ng/mL; normal range 0-0.5) }\end{array}$ & $0.2(0.1)$ \\
\hline Increased & $1(6.3 \%)$ \\
\hline $\begin{array}{l}\text { C-reactive protein } \\
\text { (mg/L; normal range } 0.0-10.0 \text { ) }\end{array}$ & $50.6(42.7)$ \\
\hline Increased & $12(75 \%)$ \\
\hline \multicolumn{2}{|l|}{ Prognosis } \\
\hline Discharge & $16(100 \%)$ \\
\hline Death & 0 \\
\hline
\end{tabular}

Data are presented as n (\%) and means (SD). "Increased" refers to over the upper limit of the normal range, and "decreased" refers to below the lower limit of the normal range. 

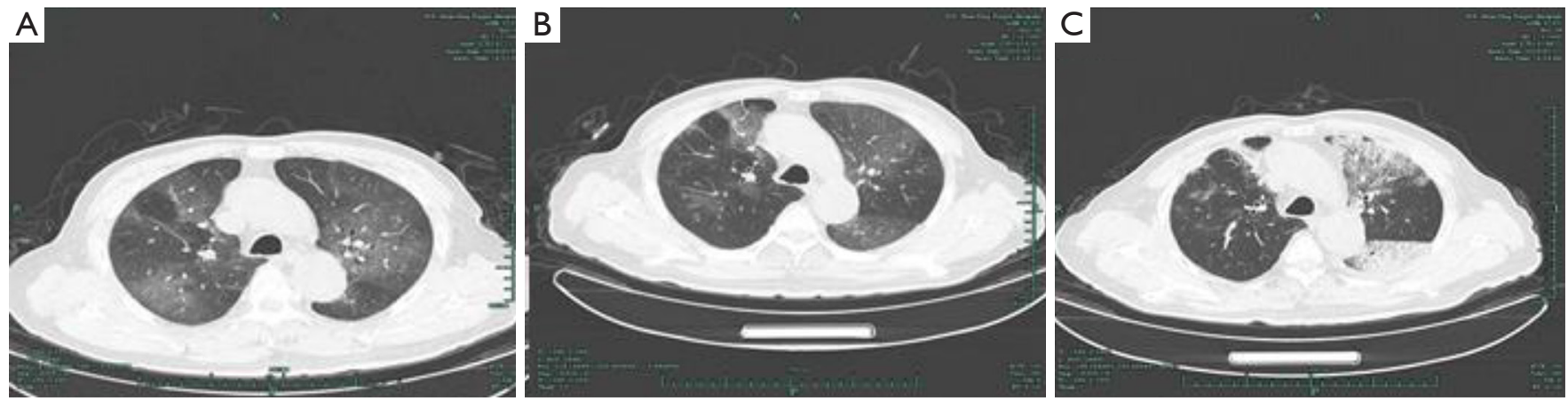

Figure 1 Thin slice CT scans in a 70-year-old man patient with COVID-19 pneumonia. (A) Day 7 after symptom onset: multiple bilateral ground-glass opacities; (B) day 17 after symptom onset: focal intralobular septal thickening in the right upper lobes; (C) day 22 after symptom onset: left-sided subpleural patchy consolidation, with a small amount of pleural effusion.
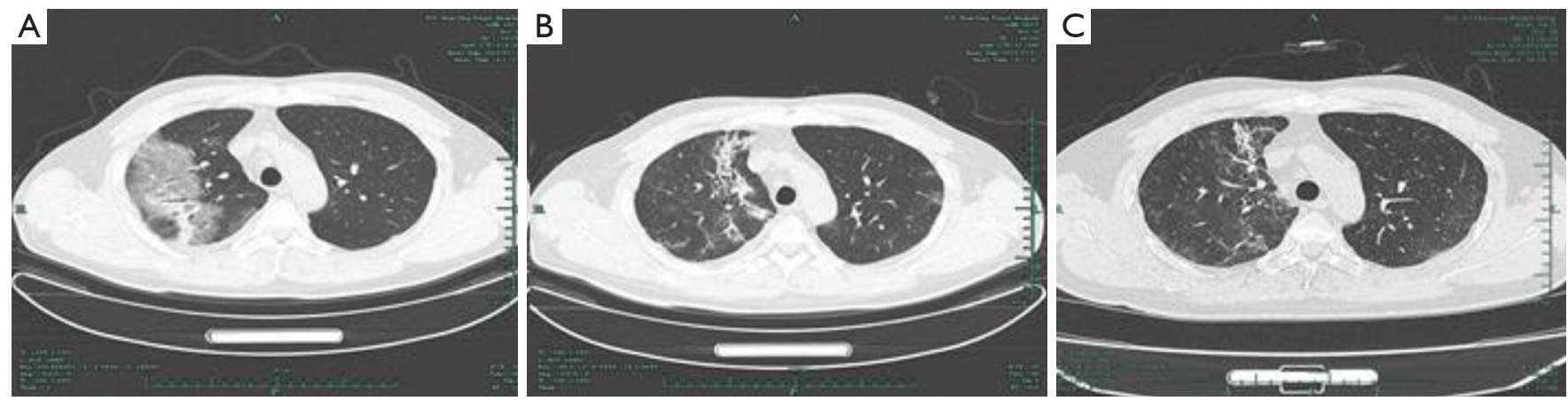

Figure 2 Thin slice CT scans in a 45-year-old man patient with COVID-19 pneumonia. (A) Day 7 after symptom onset: ground glass opacity and consolidation of the upper lobe of the right lung near the pleura; (B) day 16 after symptom onset: previous ground glass opacity and consolidation being dissipated into irregular linear opacities; $(\mathrm{C})$ following further resolution of the lesions, the patient was discharged from hospital after the final scan.

inhaled oxygen concentration was $50 \%$, the inspiratory positive airway pressure (IPAP) was $10 \mathrm{cmH}_{2} \mathrm{O}$, and expiratory positive airway pressure (EPAP) was $4 \mathrm{cmH}_{2} \mathrm{O}$. For treatment, 15 (93.8\%) patients were administered antiviral therapy, including oseltamivir, arbidol, chloroquine phosphate, and lopinavir and ritonavir tablets. Half of the patients received empirical antibiotic treatment (3 patients were treated with a single antibiotic and 5 patients were given combination therapy), and 5 (31.3\%) patients were given systematic corticosteroids. Additionally, 3 (18.6\%) patients received immunoglobulin therapy (Table 2).

None of the 16 patients died of COVID-19 pneumonia. As of March 16, 2020, all patients have been discharged and have recovered well. Only one critical patient have slight shortness of breath after activity.

\section{Discussion}

Beginning in early December 2019, COVID-19 emerged in Wuhan and spread rapidly in China. The number of infections and deaths has now exceeded those of severe acute respiratory syndrome (SARS) and the Middle East respiratory syndrome (MERS). Currently, there is no conclusive evidence that the virus originated in the Huanan seafood market. According to our data, none of the patients confirmed with COVID-19 in our center had been exposed to the Huanan seafood market. Most patients had traveled or lived in Wuhan or surrounding areas, a small minority of patients had exposure to patients with confirmed COVID-19 infection, including a family cluster infection, which suggests human-to-human transmission (5). 
In our cohort, we found that patients had relatively milder infection, especially compared with the data published from Wuhan. The mortality and incidence of severe cases have been reported as $2.6 \%$ and $15.2 \%$ respectively in the Hubei province $(2,6)$. None of our patients was sent to the ICU or died, while 1 patient with ARDS required non-invasive mechanical ventilation. Our results seem to be similar to those of patients in some cities outside Hubei province where all patients recovered. The reason for this difference is the lack of medical resources in Hubei Province during the outbreak. However, this worrying situation has improved, with the Chinese government sending a large number of medical teams to support Hubei.

Previous studies have shown that men and the elderly with chronic comorbidities are more likely to develop severe pneumonia than women or young people as a result of the weaker immune functions of these patients $(2,3,7)$. The decreased susceptibility of young women to viral infection may be related to the protection of the $\mathrm{X}$ chromosome and sex hormones, which play an important role in immune regulation. The only patient who needed ventilator assistance in our cohort was a 70-year-old male patient with diabetes and hypertension. Moreover, a 5-year-old child also was included in our study with no obvious symptoms. Because of the low immunity of children, close contact within families is the considered to be the main cause of the outbreak. According to the current situation of children's cases in various medical centers, the clinical manifestations of these patients are relatively light, with no fever or pneumonia, good prognosis, and recovery occurring within 1 to 2 weeks (8-10). At present, no critical cases in children have been reported.

As mentioned in previous studies, fever and cough are the most common symptoms in patients with COVID-19 pneumonia. Interestingly, we also found that fever was not detected in 4 patients from our study. The absence of fever manifestation makes it difficult to identify patients infected with COVID-19 in the early stage. The initial symptoms of more recently infected patients become more insidious than those of early infected patients (11). For patients with a clear epidemiological history of exposure, it is also necessary to be aware of the possibility of COVID-19 infection if rare symptoms such as diarrhea and myalgia occur. Chest CT scan has been used as the main screening and auxiliary diagnosis method of COVID-19 pneumonia. Although there exists limited descriptions of imaging features in the clinical literature, our findings are similar to those in other radiological publications. The median duration from onset of symptoms to abnormal changes in radiology was about 5 days, suggesting that a normal chest CT scan cannot exclude the diagnosis of COVID-19, so repeated radiological examinations are useful in screening these patients (12-14). We didn't analyze the incubation period because some patients had continuous exposure to contamination sources, and the uncertainty of the exact dates (recall bias) might have inevitably affected our assessment.

In concert with recent studies, nearly $70 \%$ of our patients showed lymphocytopenia in laboratory tests, with the decline of lymphocytes in severe patients being especially obvious. Lymphopenia is a significant feature of SARS-CoV and MERS-CoV infection in critical patients (15-18). The targeted invasion of SARS-CoV particles destroys the cytoplasmic components of lymphocytes and leads to destruction, while lymphocyte apoptosis is more common in critically ill patients with MERS-CoV infection (18-22). We therefore postulate that necrosis or apoptosis of lymphocytes may occur in patients with COVID-19 pneumonia. We also suggest that lymphopenia is associated with systemic inflammatory response syndrome (SIRS).

According to the existing evidence, no specialized medication to treat COVID-19 infection has been identified. The mainstay of treatment has been supportive care, and mechanical ventilation is the main adjuvant therapy for critical patients. In our study, more than $90 \%$ of patients used antiviral drugs, and nearly one-third of patients were given glucocorticoids. We mainly use interferon aerosol inhalation, combined with 1 or two antiviral drugs, including oseltamivir, arbidol, chloroquine phosphate, and lopinavir and ritonavir tablets, with the total course of treatment lasting no more than 10 days. Nearly one-third of patients had liver dysfunction, so any drug-induced liver damage caused by antiviral drugs should not be ignored. Some news drugs such as remdesivir and chloroquine phosphate are undergoing clinical trials to further evaluate their effectiveness and safety (23).

The psychological pressure of those who have been isolated for treatment also requires due attention. These patients can experience a loss of freedom, separation from relatives, uncertainty over disease status, inadequate supplies, inadequate information, and financial loss, which all contribute to an extremely adverse situation. Isolation is often an unpleasant experience for those who undergo it. If isolation is necessary, medical staff should take measures to ensure that this experience is bearable for those involved. This can be done in the following ways: informing patients 


\section{Page 8 of 9}

what is happening and why, explaining how long the quarantine will last, introducing successful experiences in curing this kind of disease, affirming the patient's own efforts, giving smiles and shaking hands with patients, providing meaningful activities for them, ensuring basic supplies are available, and increasing their confidence in fighting the disease (24).

\section{Limitations}

This study has some notable limitations. First, this is a retrospective study, and only 16 patients with confirmed COVID-19 were included. Second, we did not analyze the incubation period, which is the time from infection to symptom onset. Third, some patients' first visit was to other hospitals, where medical information could not be recorded comprehensively. Fourth, the follow-up time was also short, and some medical institutions reported that a small number of patients discharged from the hospital were positive again by RT-PCR tests; thus, the final clinic outcomes have not been completed, and further studies are still needed.

\section{Conclusions}

In conclusion, COVID-19 has spread rapidly since it was first identified in Wuhan. Compared to the symptoms of the initial patients with COVID-19 infection in Wuhan, the symptoms of those patients from Shaoxing city were relatively mild. Currently, there is no effective drug treatment or vaccine for COVID-19, and psychological counseling cannot be ignored. It is necessary to develop drugs and vaccines against COVID-19 infection as soon as possible.

\section{Acknowledgments}

Funding: This study was supported by Shaoxing Science and Technology Project.

\section{Footnote}

Reporting Checklist: The authors have completed the STROBE reporting checklist. Available at http://dx.doi. org/10.21037/atm-20-3422

Data Sharing Statement: Available at http://dx.doi. org/10.21037/atm-20-3422

Conflicts of Interest: All authors have completed the ICMJE

\section{Hu et al. Clinical characteristics of the COVID-19 in Shaoxing city}

uniform disclosure form (available at http://dx.doi. org/10.21037/atm-20-3422). The authors have no conflicts of interest to declare.

Ethical Statement: The authors are accountable for all aspects of the work in ensuring that questions related to the accuracy or integrity of any part of the work are appropriately investigated and resolved. The study was approved by the Institutional Review Board of the Affiliated Hospital of Shaoxing University, and written informed consent was obtained from patients involved before enrolment.

Open Access Statement: This is an Open Access article distributed in accordance with the Creative Commons Attribution-NonCommercial-NoDerivs 4.0 International License (CC BY-NC-ND 4.0), which permits the noncommercial replication and distribution of the article with the strict proviso that no changes or edits are made and the original work is properly cited (including links to both the formal publication through the relevant DOI and the license). See: https://creativecommons.org/licenses/by-nc-nd/4.0/.

\section{References}

1. Lu H, Stratton CW, Tang YW. Outbreak of Pneumonia of Unknown Etiology in Wuhan China: the Mystery and the Miracle. J Med Virol 2020;92:401-2.

2. Huang C, Wang Y, Li X, et al. Clinical features of patients infected with 2019 novel coronavirus in Wuhan, China. Lancet 2020;395:497-506.

3. Chen N, Zhou M, Dong X, et al. Epidemiological and clinical characteristics of 99 cases of 2019 novel coronavirus pneumonia in Wuhan, China: a descriptive study. Lancet 2020;395:507-13.

4. World Health Organization. Coronavirus disease (COVID-19) outbreak. Available online: https://www. who.int

5. Chan JF, Yuan S, Kok KH, et al. A familial cluster of pneumonia associated with the 2019 novel coronavirus indicating person-to-person transmission: a study of a family cluster. Lancet 2020;395:514-23.

6. Yang X, Yu Y, Xu J, et al. Clinical course and outcomes of critically ill patients with SARS-CoV-2 pneumonia in Wuhan, China: a single-centered, retrospective, observational study. Lancet Respir Med 2020;8:475-81.

7. de Wit E, van Doremalen N, Falzarano D, et al. SARS and MERS: recent insights into emerging coronaviruses. Nat 
Rev Microbiol 2016;14:523-34.

8. The State Council's Joint Prevention and Control Mechanism for Pneumonia Epidemic in Response to New Coronavirus Infection. Notice on prevention and control of pneumonia in children and pregnant women with new coronavirus infection. Feb 3, 2020. Available online: http:// www.ljxw.gov.cn/news-93789.shtml (accessed Feb 4, 2020; in Chinese).

9. Shen K, Yang Y, Wang T, et al. Diagnosis, treatment, and prevention of 2019 novel coronavirus infection in children: Experts' consensus statement. World J Pediatr 2020. [Epub ahead of print].

10. $\mathrm{Xu} X W, \mathrm{Wu} X X$, Jiang $\mathrm{XG}$, et al. Clinical findings in a group of patients infected with the 2019 novel coronavirus (SARS-Cov-2) outside of Wuhan, China: retrospective case series. BMJ 2020;368:m606.

11. Chen Z, Hu J, Zhang Z, et al. Caution: clinical characteristics of COVID-19 patients are changing at admission. Lancet 2020. Available at SSRN: https://ssrn. com/abstract=3546044 or http://dx.doi.org/10.2139/ ssrn. 3546044

12. Chung M, Bernheim A, Mei XY, et al. CT imaging features of 2019 novel coronavirus (2019-nCoV). Radiology 2020;295:202-7.

13. Shi H, Han X, Jiang N, et al. Radiological findings from 81 patients with COVID-19 pneumonia in Wuhan, China: a descriptive study. Lancet Infect Dis 2020;20:425-34.

14. Pan Y, Guan H. Imaging changes in patients with 2019nCoV. Eur Radiol 2020. [Epub ahead of print].

15. Ksiazek TG, Erdman D, Goldsmith CS, et al. A novel coronavirus associated with severe acute respiratory syndrome. N Engl J Med 2003;348:1953-66.

Cite this article as: $\mathrm{Hu} W$, Chen $\mathrm{X}, \mathrm{He} \mathrm{B}$, Yuan S, Zhang $\mathrm{X}$, Wu G, Liu J, Xu L, Cha W, Xu M, Sun X, Shen H. Clinical characteristics of 16 patients with COVID-19 infection outside of Wuhan, China: a retrospective, single-center study. Ann Transl Med 2020;8(10):642. doi: 10.21037/atm-20-3422
16. Drosten C, Gunther S, Preiser W, et al. Identification of a novel coronavirus in patients with severe acute respiratory syndrome. N Engl J Med 2003;348:1967-76.

17. Kuiken T, Fouchier RAM, Schutten M, et al. Newly discovered coronavirus as the primary cause of severe acute respiratory syndrome. Lancet 2003;362:263-70.

18. de Groot RJ, Baker SC, Baric RS, et al. Middle East respiratory syndrome coronavirus (MERS-CoV): announcement of the Coronavirus Study Group. J Virol 2013;87:7790-2.

19. Zaki AM, van Boheemen S, Bestebroer TM, et al. Isolation of a novel coronavirus from a man with pneumonia in Saudi Arabia. N Engl J Med 2012;367:1814-20.

20. Yin Y, Wunderink RG. MERS, SARS and other coronaviruses as causes of pneumonia. Respirology 2018;23:130-7.

21. Kim KH, Tandi TE, Choi JW, et al. Middle East respiratory syndrome coronavirus (MERS-CoV) outbreak in South Korea, 2015: epidemiology, characteristics and public health implications. J Hosp Infect 2017;95:207-13.

22. WHO. Middle East respiratory syndrome coronavirus (MERS-CoV). Available online: https://www.who.int/ emergencies/mers-cov/en/ (accessed Jan 27, 2020)

23. Sheahan TP, Sims AC, Leist SR, et al. Comparative therapeutic efficacy of remdesivir and combination lopinavir, ritonavir, and interferon beta against MERSCoV. Nat Commun 2020;11:222.

24. Brooks SK, Webster RK, Smith LE, et al. The psychological impact of quarantine and how to reduce it: rapid review of the evidence. Lancet 2020;395:912-20. 